\title{
Critical Power Determination with Ergometry Rowing: Relation to Rowing Performance
}

\author{
Manabu Shimoda and Yasuo Kawakami* \\ *Faculty of Sport Sciences, Waseda University \\ 2-579-15, Mikajima, Tokorozawa, Saitama 359-1192 Japan \\ ykawa@waseda.jp \\ [Received December 24, 2003 ; Accepted January 24, 2005]
}

\begin{abstract}
The relationships between critical power (CP) and anaerobic work capacity (AWC), and the rowing performance in a $2000 \mathrm{~m}$ ergometry rowing effort were assessed. Nine male university rowers performed three tests: 1) critical power determination, 2) $2000 \mathrm{~m}$ simulated rowing and 3) $\dot{\mathrm{V}}_{2} \max$ test. The $\mathrm{CP}$ and $\mathrm{AWC}$ were determined from the regression between work and time to exhaustion, derived from three exhaustive trials at 70,60 , and $50 \%$ of the maximal power. The $2000 \mathrm{~m}$ simulated rowing performance was higher for subjects with higher $\mathrm{CP}$ independent of $\mathrm{AWC}$. The mean power throughout the $2000 \mathrm{~m}$ simulated rowing correlated significantly with $C P(r=0.87)$ and the absolute $\dot{V} O_{2} m a x(r=0.71)$, but not with AWC. CP also influenced the pattern of changes in power over the $2000 \mathrm{~m}$ simulated rowing. We conclude that the $C P$ is a useful indicator of rowing performance and may be efficacious for monitoring the training effects in rowing.
\end{abstract}

Keywords: critical power, aerobic and anaerobic energy supply, $2000 \mathrm{~m}$ ergometric rowing

[International Journal of Sport and Health Science Vol.3, 21-26, 2005]

\section{Introduction}

The critical power $(\mathrm{CP})$ concept is based on a liner relationship observed between total work performed and time to exhaustion (Work-Time relationship) (Monod and Scherrer, 1965). In this concept, the slope of the linear regression line is referred to as a critical power, and is defined theoretically as the highest power attainable during exercise without fatigue (Monod and Scherrer, 1965). The CP is thought to represent the rate of ATP synthesis by the aerobic energy supply system (Poole et al., 1990; Housh et al., 1991; and McLellan and Cheung, 1992). A y-intercept, the second parameter of the relationship, is believed to represent anaerobic capacity of an individual, and is referred to as an anaerobic work capacity (AWC) (Monod and Scherrer, 1965; Poole et al., 1988; and Jenkins and Quigley, 1991). The AWC is regarded as a reflection of energy resources yielded through the phosphoric reaction and the anaerobic metabolism (Bishop et al., 1998). The capacity of an individual in the aerobic and anaerobic energy supplying systems can, therefore, be estimated at the same time by measuring the Work-Time relationship.

The critical power concept seems to be applicable to a wide range of sporting events, but there are few studies in rowing (Kennedy and Bell, 2000). Previous studies have shown that $\mathrm{CP}$ and AWC respectively reflect the aerobic and anaerobic aspect of exercise in running (Kachouri et al., 1996; and Pepper et al., 1992), cycling (Jenkins and Quigley, 1990; and Mclellan and Cheung, 1992) and swimming (Wakayoshi et al., 1992, 1993). However, the relationships between $\mathrm{CP}$ and AWC and rowing performance remain unclear. Competitive rowing is regarded as an endurance sport and a close relationship exists between the rowing performance and the aerobic capacity of rowers (Kramer et al., 1994; Cosgrove et al., 1999; Yoshiga et al., 2000; and Yoshiga et al., 2003). It has been also suggested that anaerobic energy supply plays a significant role at onset of a rowing race (Secher, 1993; and Shephard 1998). We thus tested whether CP and/or AWC correlate with rowing performance. The aims of this study were to determine CP and AWC based 


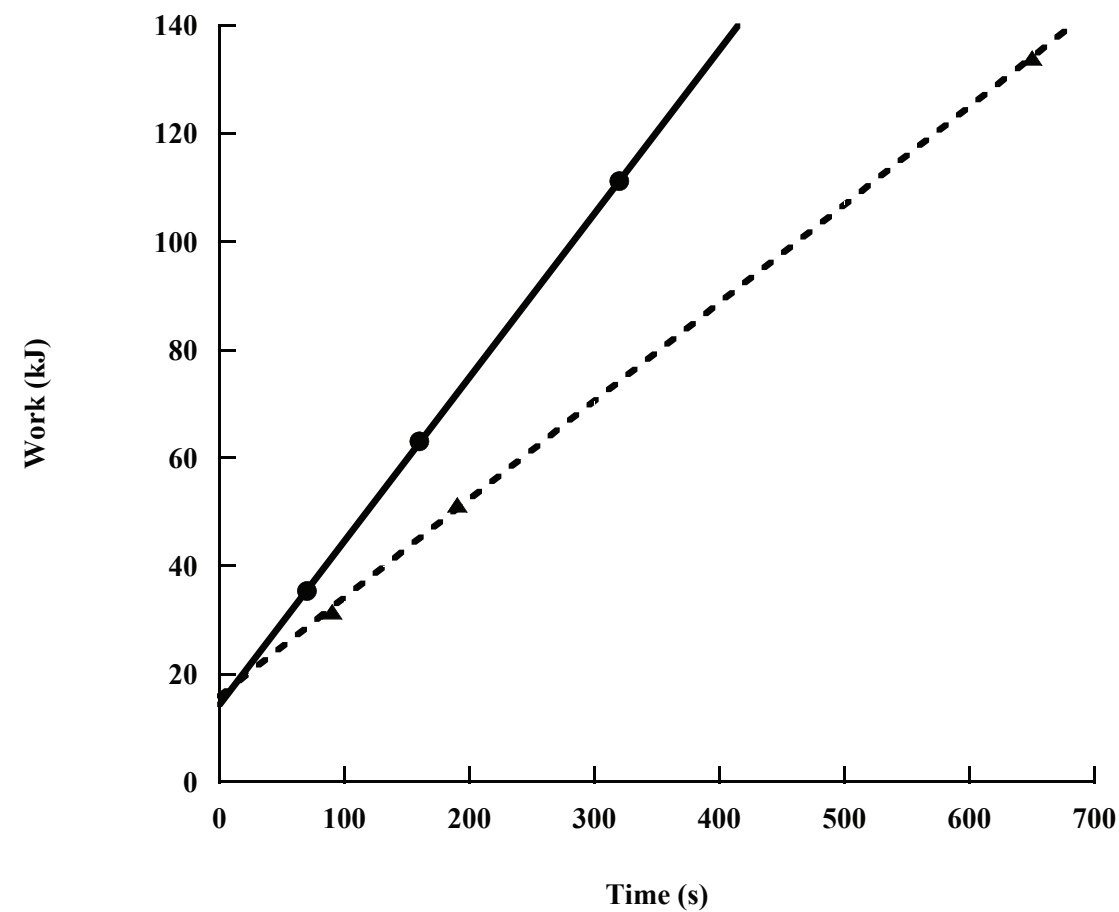

Fifure 1 The Work-Time relationship derived from three target trials for two subjects. In this example, Solid and dotted regression line showed the WorkTime relationship for the subjects with the highest $\left(\mathrm{CP}\right.$ is $0.303 \mathrm{~kJ} \mathrm{~s}^{-1}$ or $303 \mathrm{~W}$, and AWC is $14.3 \mathrm{~kJ})$ and the lowest $\mathrm{CP}\left(\mathrm{CP}\right.$ is $0.182 \mathrm{~kJ} \mathrm{~s}^{-1}$ or $182 \mathrm{~W}$, and AWC is $15.9 \mathrm{~kJ}$ ) respectively.

on the critical power concept, and to evaluate the relationship between these parameters and rowing performance of $2000 \mathrm{~m}$ ergometry rowing.

\section{Methods}

\subsection{Subjects}

Nine male university rowers volunteered to participate in this study. Their age, height and body mass were $19.8 \pm 0.8 \mathrm{yr}, 177.2 \pm 4.1 \mathrm{~cm}$ and $73.9 \pm$ $7.4 \mathrm{~kg}$ respectively. They all had experience of 2000 $\mathrm{m}$ rowing competition, ranging from 1 to 3 years, and trained regularly on a Concept II rowing ergometer. All procedures were undertaken with the informed consent of the subjects and the approval of the local ethics committee. This study consisted of three tests: critical power and rowing performance tests performed with a Concept II rowing ergometer and a $\dot{\mathrm{V}} \mathrm{O}_{2}$ max test performed with a bicycle ergometer.

\subsection{Critical power test}

Each subject performed three exhaustive trials on a rowing ergometer (Concept II , Model C, Morrisville, VT, USA) at three different power levels that were determined from a preceding maximal power test. The maximal power was the highest value displayed on the monitor of the ergometer when each subject rowed ten strokes with maximal effort three times. The 70, 60, and 50\% values relative to the maximal power were used as a target (70, 60, and 50\% MAX trial respectively). The 70 and $60 \%$ MAX trials were performed on the same day, separated by over 30 minutes of rest. The $50 \%$ MAX trial was performed after 1 to 3 days from the prior two trials because in a pilot study we found that the subjects were exhausted by the 50\% MAX trial and could not perform it with the other trials. However, the effect of the order of trails on estimation of $\mathrm{CP}$ and AWC needs further investigation. The ergometer was equipped with a monitor displaying an estimated distance, split time every $500 \mathrm{~m}$, power output and heart rate (HR) which was determined by telemetered heart rate monitor (Vantage NV, Polar Electro, Finland). The power output displayed on the monitor was recorded every 10 seconds.

In each trial, all subjects maintained the target power output as long as possible. Each subject was regarded as exhausted and the test was terminated when the power decreased more than $10 \%$ from the target. The time to exhaustion was defined as the duration when the target power output was first attained until the instance when the subject was unable to maintain the required power output.

The work (power $\times$ time to exhaustion) plotted against time to exhaustion gave a linear relationship (Figure 1). The CP was determined as the slope of the linear regression between the work and time to exhaustion. The AWC was determined as the $y$-intercept of the linear regression (Monod and 
Table 1 Time to exhaustion, mean power, and work determined from three target trials.

\begin{tabular}{lccc}
\hline & $\mathbf{7 0} \%$ MAX & $\mathbf{6 0 \%}$ MAX & $50 \%$ MAX \\
\hline Time to exhaustion (s) & $64.4 \pm 15.9$ & $153.3 \pm 41.8$ & $395.6 \pm 129.4$ \\
Mean power $(W)$ & $480.9 \pm 53.7$ & $356.1 \pm 41.1$ & $301.3 \pm 45.0$ \\
Work (kJ) & $30.7 \pm 7.1$ & $53.9 \pm 13.8$ & $115.1 \pm 24.2$ \\
\hline
\end{tabular}

before and after each test with certified gas mixture.

After a 1 min resting period sitting on the bicycle ergometer, the subjects began to cycle against a resistance load of 0.5 $\mathrm{kp}$. The resistance load was increased by $0.5 \mathrm{kp}$

Scherrer, 1965; and Hill, 1993).

\subsection{Rowing performance test}

A $2000 \mathrm{~m}$ simulated rowing on a Concept II owing ergometer ("time-trial" mode) was employed as a rowing performance test. After 10 minutes warm-up and a short rest, all subjects performed with their maximal effort. They were instructed to "simulate the race", starting with an initial spurt followed by a constant pace at their preferable stroke rate. The mean power and split time were recorded.

\subsection{Determination of maximal oxygen uptake}

The subjects performed a continuous incremental test to volitional exhaustion on a bicycle ergometer (Monark 814E, Sweden). A bicycle ergometer was used because a rowing ergometer was not available in the laboratory. According to a previous study that found no significant difference between rowing and bicycle ergometers in $\dot{\mathrm{V}} \mathrm{O}_{2} \max$ (Cunningham et al., 1975), we consider that $\dot{\mathrm{V}}{ }_{2} \max$ values were not affected by the apparatus used. The $\dot{\mathrm{V}} \mathrm{O}_{2}$ max values obtained in this study therefore might be equal or smaller than those measured by using a rowing ergometer (Secher, 1993). Throughout the test, expired air was sampled continuously breath by breath (Respiromonitor RM300i, Minato Medical Science, Japan). Oxygen consumption was measured by using a gas analyzer (Medical gas analyzer MG360, Minato Medical Science, Japan). A 3-lead electrocardiogram (ECG) (Bio-scope 5211, Fukuda ME, Japan) was monitored continuously during the test to measure the heart rate. The $\dot{\mathrm{V}}_{2}$ and HR were averaged every 15 seconds. Calibration of the air flow rate for expired air measures was performed before each test using a calibrated syringe. The gas analyzers were calibrated every 4 min until $12 \mathrm{~min}$ and thereafter increased by $0.5 \mathrm{kp}$ per minute until exhaustion. Subjects were encouraged to continue the test until exhaustion. The pedaling rate was maintained at $60 \mathrm{rpm}$ during the test. All testing was performed at a constant room temperature $\left(17.8^{\circ} \mathrm{C}\right)$ and humidity $(38 \%)$.

The maximal oxygen uptake was considered to be achieved from 1) oxygen consumption plateaued and 2) $R$ value was 1.2 or greater. Maximal values of heart rate (HRmax), minute ventilation ( $\left.\dot{\mathrm{V}} \mathrm{O}_{2} \mathrm{Emax}\right)$, and carbon dioxide production $\left(\dot{\mathrm{V}} \mathrm{CO}_{2} \mathrm{max}\right)$ were also determined.

\subsection{Statistics}

Values are presented as means $\mathrm{SD}$, unless otherwise stated. Pearson's correlation coefficient (r) was used to examine the interrelationships between the variables. A one-way analysis of variance (ANOVA) was performed to analyze the mean power and split time of each $500 \mathrm{~m}$ during the $2000 \mathrm{~m}$ simulated rowing. To adjust for multiple comparisons when ANOVA showed a significant difference between groups, Fisher LSD post-hoc test was used to identify which group differences accounted for the significant $P$ value. In each statistical analysis, the significance was accepted at the 0.05 level.

\section{Results}

\subsection{Critical power test}

The mean maximal power was $620 \pm 91 \mathrm{~W}$. The time to exhaustion, mean power and work at the three trials are shown in Table 1. Highly linear relationships between the work and time to exhaustion were observed for all subjects. The $\mathrm{CP}$ and the AWC were $262 \pm 37 \mathrm{~W}$ and $14.0 \pm 3.6 \mathrm{~kJ}$ respectively. The 


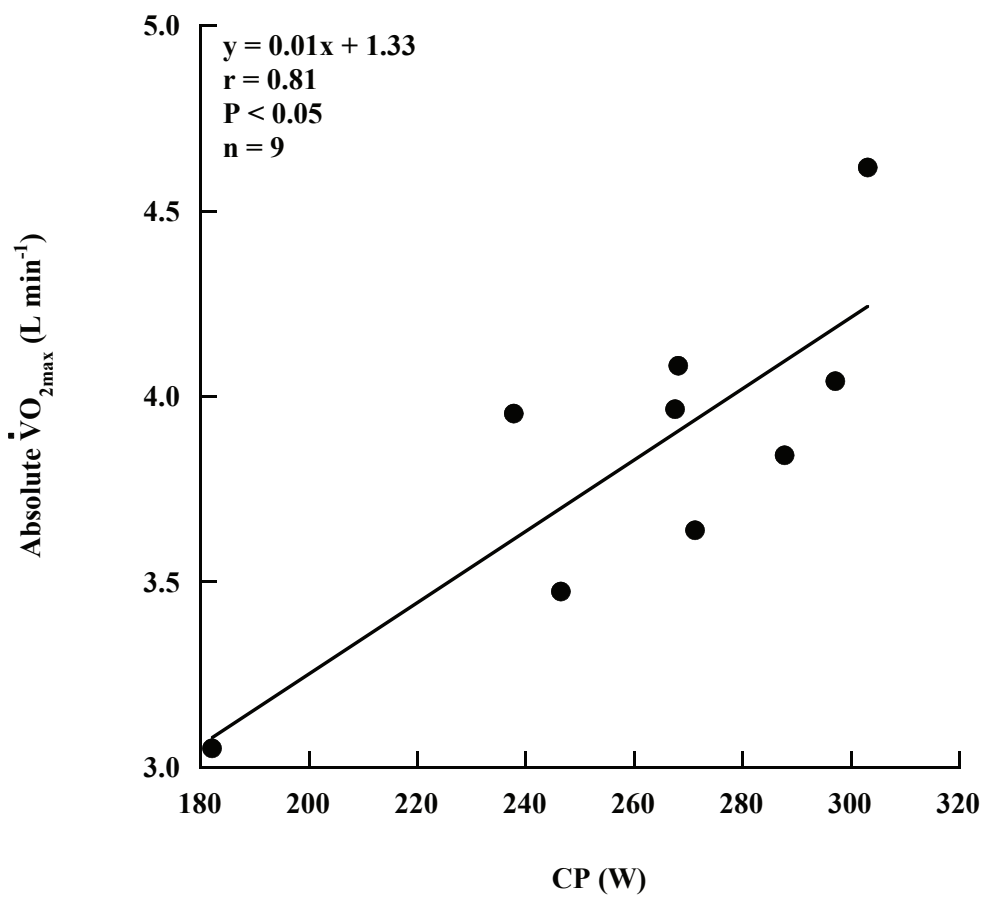

Fifure 2 The relationships between absolute $\dot{\mathrm{V}}_{2} \max$ and $\mathrm{CP}(P<0.05)$.

Table 2 Split time and mean power for each $500 \mathrm{~m}$ during the $2000 \mathrm{~m}$ simulated rowing.

\begin{tabular}{lcccc}
\hline Distance (m) & $0-500$ & $500-1000$ & $1000-1500$ & $1500-2000$ \\
\hline Split time (s) & $99.3 \pm 2.9$ & $103.2 \pm 3.3$ & $105.7 \pm 4.7$ & $105.9 \pm 5.6$ \\
Mean power (W) & $359 \pm 31$ & $320 \pm 31$ & $300 \pm 40$ & $297 \pm 51$ \\
\hline
\end{tabular}

Table 3 Selected variables of all subjects. Mean power in the $2000 \mathrm{~m}$ simulated rowing represents an average of mean powers of four $500 \mathrm{~m}$ sections.

\begin{tabular}{cccccc}
\hline & Total time & Mean power & CP & AWC & Absolute VO max $^{2}$ \\
& S & W & W & kJ & L min-1 \\
\hline A & 393 & 370.0 & 303 & 14.3 & 4.62 \\
B & 398 & 354.7 & 271 & 22.5 & 3.64 \\
C & 405 & 336.7 & 297 & 10.9 & 4.04 \\
D & 408 & 332.9 & 288 & 12.3 & 3.84 \\
E & 415 & 311.7 & 268 & 10.2 & 3.97 \\
F & 417 & 308.4 & 268 & 12.1 & 4.08 \\
G & 421 & 300.9 & 246 & 13.9 & 3.47 \\
H & 432 & 278.2 & 238 & 13.7 & 3.95 \\
I & 437 & 268.5 & 182 & 15.9 & 3.05 \\
Mean & 414.0 & 318.0 & 262 & 14.0 & 3.85 \\
SD & 14.7 & 33.7 & 37 & 3.6 & 0.44 \\
\hline
\end{tabular}

standard errors of the mean (SEM) were $8 \pm 4 \mathrm{~W}$ for $\mathrm{CP}$ and $1.5 \pm 1.2 \mathrm{~kJ}$ for AWC.

\section{2. $\dot{\mathrm{V}} \mathrm{O}_{2} \max$ test}

Absolute $\dot{\mathrm{V}} \mathrm{O}_{2} \max$ were $3.85 \pm 0.44 \mathrm{~L}$ min- 1 . A statistically significant and strong positive correlation was observed between CP and the absolute $\dot{\mathrm{V}} \mathrm{O}_{2} \max (\mathrm{r}$ $=0.81)($ Figure 2$)$.

\section{3. $2000 \mathrm{~m}$ simulated rowing}

The mean power and split time every $500 \mathrm{~m}$ and mean power and time of the 2000 $\mathrm{m}$ simulated rowing are shown in Table 2. During the $2000 \mathrm{~m}$ simulated rowing, the mean power and split time for $500 \mathrm{~m}$ continued to decline by the third $500 \mathrm{~m}$, and no significant difference was observed between the mean power of the third 500 $\mathrm{m}$ and the fourth $500 \mathrm{~m}$. The decline of the mean power during $500 \mathrm{~m}$ was largest between the first $500 \mathrm{~m}$ and the second $500 \mathrm{~m}$ (Table 2).

The $2000 \mathrm{~m}$ simulated rowing performance was higher for all subjects with higher $\mathrm{CP}$, independent of AWC, excluding one subject (Table 3). The mean power and total time throughout the $2000 \mathrm{~m}$ simulated rowing correlated significantly with $\mathrm{CP}(\mathrm{r}=0.87$ and $\mathrm{r}=0.88$ respectively) and the absolute $\dot{\mathrm{V}} \mathrm{O}_{2}$ max $(\mathrm{r}=0.71$ only for the mean power), but did 
not correlate with AWC. The mean power and split time of each $500 \mathrm{~m}$ in the $2000 \mathrm{~m}$ simulated rowing significantly correlated with $\mathrm{CP}$ (mean power: $\mathrm{r}=$ $0.69 \sim 0.87$ and split time: $\mathrm{r}=0.68 \sim 0.89$ ).

\section{Discussion}

The Work-Time relationship was investigated by using a rowing ergometer in the present study. The subjects carried out three trials (70,60 and $50 \%$ MAX) in order to estimate CP and AWC. The appropriate exercise duration for each work load has been studied for estimating $\mathrm{CP}$ and AWC in the critical power concept. If the trials range from 1 to 10 minutes, the regression between the exercise duration and work load gives a good fit (Carnevale and Gaesser, 1991; Jenkins and Quigley, 1992, 1993; and Hill, 1993). The exercise durations of the trials in the present study were within that range (1 to 10 minutes), which highly correlated with the work load $(\mathrm{R} 2=0.997$ to 1$)$. We conclude, therefore, that the determination of the target power output in the present study was appropriate.

The reliability and accuracy of AWC, the second parameter of the critical power concept, has been evaluated with SEM. Hill (1993) stated that AWC was an acceptable measure of anaerobic capacity when SEM was $<10 \%$ of AWC. The SEM of AWC in the present study was slightly greater than this range $(\mathrm{SEM}=10.5 \%$ of $\mathrm{AWC})$. It is suggested that the exercise duration of about three minutes is required to maximize the anaerobic ATP yield (Bangsbo et al., 1990), and that AWC is influenced by the duration of trials (Bishop et al., 1998). Thus the SEM of AWC would be reduced if trials with longer duration were further included.

The strong correlations between $\mathrm{CP}$ and both the mean power and total time in the $2000 \mathrm{~m}$ simulated rowing, and between $\mathrm{CP}$ and absolute $\dot{\mathrm{V}} \mathrm{O}_{2}$ max, indicate that the aerobic capacity of rowers are closely related with their rowing performance. The present relationships between the rowing performance and oxygen uptake and between the rowing performance and $\mathrm{CP}$ are in line with results of previous studies that showed a close relationship between rowing performance and the absolute $\dot{\mathrm{V}} \mathrm{O}_{2} \max$ (Kramer et al., 1994; Cosgrove et al., 1999; and Yoshiga et al., 2003). Furthermore, the $2000 \mathrm{~m}$ simulated rowing performance was higher for a subject with higher $\mathrm{CP}$, independent of AWC, excluding one subject. This indicates that rowing performance is more affected by $\mathrm{CP}$ than AWC because the aerobic capacity of rowers is predominantly required throughout a rowing race (Hagerman et al., 1978). The present result also confirms the correlation between rowing performance and critical velocity (with velocity substituted for power) (Kennedy and Bell, 2000). These findings support the notion that the rowing performance can be evaluated through $\mathrm{CP}$, without measuring $\dot{\mathrm{V}} \mathrm{O}_{2}$ max as an index of aerobic capacity of rowers.

A previous study has suggested that the initial spurt may help to increase the work throughout the simulated rowing (Secher, 1993). However, the mean power and split time in the first $500 \mathrm{~m}$ did not correlate with AWC; instead, it correlated with CP. Therefore, the first $500 \mathrm{~m}$ appears to be performed mainly by the use of aerobic energy supply, although the initial spurt ( $\sim 10$ strokes at the onset of exercise) would have been performed both aerobically and anaerobically. Further studies are required for the physiological explanation of the contribution of AWC to rowing performance. It is expected that the difference of the physiological mechanisms between $\mathrm{CP}$ and $\mathrm{AWC}$ in rowing will be defined through longitudinal studies of training effects.

Aerobic and endurance type training induces an increase in CP (Poole et al., 1990; and Jenkins and Quigley, 1990, 1992), and anaerobic and high-intensity type training induces an increase in AWC (Jenkins and Quigley, 1990, 1993). The CP and $\mathrm{AWC}$, therefore, can be used to monitor the effect of training in terms of aerobic and anaerobic performance. These parameters can be measured at the same time in the critical power test.

In conclusion, the $\mathrm{CP}$ derived from ergometry rowing is an index for evaluating rowing performance. The CP is thus a useful indicator for monitoring the training effects in rowing, and the present method has practical importance because the rowers commonly use the rowing ergometer in their training. 


\section{References}

Bangsbo, J., Gollnick, P.D., Graham, T.E., Juel, C., Kiens, B., Mizuno, M. and Saltin, B. (1990). Anaerobic energy production and $\mathrm{O} 2$ deficit-debt relationship during exhaustive exercise in humans. Journal of Physiology, 42, 539-559.

Bishop, D., Jenkins, D.G. and Howard, A. (1998). The critical power function is dependent on the duration of the predictive exercise tests chosen. International Journal of Sports Medicine, $19,125-129$.

Carnevale, T.J. and Gaesser, G.A. (1991). Effects of pedaling speed on the power-duration relationship for high-intensity exercise. Medicine and Science in Sports and Exercise, 23, 242-246.

Cosgrove, N.J., Wilson, J., Watt, D. and Grant, S.F. (1999). The relationship between selected physiological variables of rowers and rowing performance as determined by a $2000 \mathrm{~m}$ ergometer test. Journal of Sports Sciences, 17, 845-852.

Cunningham,D.A., Goode,P.B.,Critz,J.B.(1975). Cardiorespiratory response to exercise on a rowing and bicycle ergometer. Medicine and Science in Sports, 7, 37-43.

Hagerman, F.C., Conners, M.C., Gault, J.A., Hagerman, G.R. and Polinski, W.J. (1978). Energy expenditure during simulated rowing. Journal of Applied Physiology, 45, 87-93.

Hill D. W. (1993). The critical power concept: A review. Sports Medicine, 16, 237-254.

Housh, T.J., Johnson, G.O., McDowell, S.L., Housh, D.J. and Pepper, M.L. (1991). Physiological responses at the fatigue threshold. International Journal of Sports Medicine, 12, 305-308.

Jenkins, D.G. and Quigley, B.M. (1990). Blood lactate in trained cyclists during cycle ergometry at critical power. European Journal of Applied Physiology and Occupational Physiology, $61,278-283$.

Jenkins, D.G. and Quigley, B.M. (1991). The y-intercept of the critical power function as a measure of anaerobic work capacity. Ergonomics, 34, 13-22.

Jenkins, D.G. and Quigley, B.M. (1992). Endurance training enhances critical power. Medicine and Science in Sports and Exercise, 24, 1283-1289.

Jenkins, D.G. and Quigley, B.M. (1993). The influence of high intensity exercise training on the Wlim-Tlim relationship. Medicine and Science in Sports and Exercise, 25, 275-282.

Kachouri, M., Vandewalle, H., Billat, V., Huet, M., Thomaidis, M., Jousselin, E. and Monod, H. (1996). Critical velocity of continuous and intermittent running exercise: An example of the limits of the critical power concept. European Journal of Applied Physiology, 73: 484-487.

Kennedy, M.D.J. and Bell, G.J. (2000). A comparison of critical velocity estimates to actual velocities in predicting simulated rowing performance. Canadian Journal of Applied Physiology, 25, 223-235.

Kramer, J.F., Leger, A., Paterson, D.H. and Morrow, A. (1994). Rowing performance and selected descriptive, field and laboratory variables. Canadian Journal of Applied Physiology, 19, 174-184.

McLellan, T.M. and Cheung, K.S.Y. (1992). A comparative evaluation of the individual anaerobic threshold and the critical power. Medicine and Science in Sports and Exercise, 24, 543-550.

Monod, H. and Scherrer, J. (1965). The work capacity of synergic muscle group. Ergonomics, 8, 329-338.

Pepper, M.L., Housh, T.J. and Johnson, G.O. (1992). The accuracy of the critical velocity test for predicting time to exhaustion during treadmill running. International Journal of Sports Medicine, 13, 121-124.

Poole, D.C., Ward, S.A., Gardner, G.W. and Whipp, B. J. (1988). A metabolic and respiratory profile or the upper limit for prolonged exercise in man. Ergonomics, 31, 1265-1279.

Poole, D.C., Ward, S.A. and Whipp, B.J. (1990). The effects of training on the metabolic and respiratory profile of high-intensity cycle ergometer exercise. European Journal of Applied Physiology and Occupational Physiology, 59, 421-429.

Secher, N.H. (1993). Physiological and biomechanical aspects of rowing. Sports Medicene, 15, 24-42.

Shephard, R.J. (1998). Science and medicine of rowing; A review. Journal of Sports Sciences, 16, 603-620.

Wakayoshi, K., Ikuta, K., Yoshida, T., Udo, M., Moritani, T., Mutoh, Y. and Miyashita, M. (1992). Determination and validity of critical velocity as an index of swimming performance in the competitive swimmer. European Journal of Applied Physiology, 64, 153-157.

Wakayoshi, K., Yoshida, T., Udo, M., Harada, T., Moritani, T., Mutoh, Y. and Miyashita, M. (1993). Does critical swimming velocity represent exercise intensity at maximal lactate steady state? European Journal of Applied Physiology, 66, 90-95.

Yoshiga, C., Kawakami, Y., Okamura, K., Oka, J. and Higuchi, M. (2000). Serum lipoprotein cholesterols in male collegiate rowers. Advances in Exercise and Sports Physiology, 7:33-37.

Yoshiga, C. and Higuchi, M. (2003). Rowing performance of female and male rowers. Scandinavian Journal of Medicine and Science in Sports, 13:317-321.

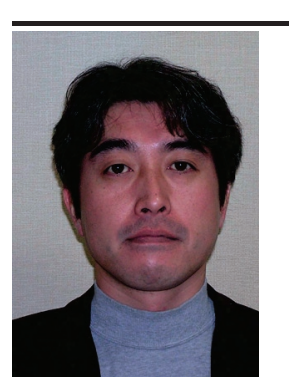

\section{Name:}

Manabu Shimoda

Brief Biographical History:

1997-2002 PhD program, Department of Life Sciences, The University of Tokyo

Main Works:

- Shimoda, M. and Kawakami, Y. Effect of rowing power consistency on velocity of a rowing shell: a study on varsity rowers. Journal of Training Science for Exercise and Sport, 16: 19-26, 2004. (in Japanese)

\section{Membership in Learned Societies:}

- The Japanese Society of Physical Fitness and Sports Medicine

- The Japan Society of Physical Education, Health and Sport Sciences 